\title{
SPATIAL MONOPOLY WITH UPGRADES OF DURABLE GOODS
}

\section{Yong-cong Yang, Pu-yan Nie, Zhao-hui Wang, Zheng-xun Tan*}

\begin{abstract}
This paper establishes a two-stage Hotelling model to identify the implications of the upgrades of durable goods produced by a spatial monopoly. The major findings indicate that, due to the positive effects on profits of the upgrading of products, the monopoly has the motivation to launch upgraded versions with high quality instead of solely producing products with low quality. The monopoly, meanwhile, would not make a commitment to either the high-quality products or the low-quality ones. In addition, the price of the low-quality products decreases as upgraded ones appear on the market in a second stage, since no consumers would store the low-quality products for future consumption.
\end{abstract}

Keywords: durable goods, spatial monopoly, commitment, upgrade, game theory JEL Classification: C61, C72, D40, L10

\section{Introduction}

Many goods are durable to some degree, implying a relatively longer life before expiry date than consumables. More specifically, durable goods are defined as those that can last for a relatively long time, including cars, appliances, business equipment, electronic equipment, home furnishings and fixtures, housewares and accessories, photographic equipment, recreational goods, sporting goods, toys and games, etc. Therefore, durable goods are exceedingly popular throughout the world. As is known, the production strategy and the selling strategy of one product are not solely determined by the features of firms and market structure, but also relate to the product characteristics. As a result, the strategies of durable goods should be different from those of consumables. It is extremely important to acknowledge the strategies of firms on the durable goods market.

There is extensive research on durable goods in the fields of economics and management (see Anton and Das Varm, 2005; Barsky et al., 2007; Nie, 2009; Goering, 2008;

* Yong-cong Yang, Guangdong University of Foreign Studies, Institute of Studies for the Great Bay Area, Guangzhou, China (yangyongcong3787@sina.com);

Pu-yan Nie, Guangdong University of Finance \& Economics, Collaborative Innovation Center of Scientific Finance \& industry, Guangzhou, China (ieps2007@sina.com);

Zhao-hui Wang, Guangdong University of Finance \& Economics, Collaborative Innovation Center of Scientific Finance \& industry, Guangzhou, China (1242420635@qq.com);

Zheng-xun Tan, Guangdong University of Finance \& Economics, Collaborative Innovation Center of Scientific Finance \& industry, Guangzhou, China (tzxun1810@163.com).

This work was supported by National Natural Science Foundation of PRC (71771057), National Natural Science Foundation of PRC (71703028), and Natural Science Foundation of Guangdong Province (2017A030310615).

The authors declare that there is no conflict of interests regarding the publication of this article. 
and the references mentioned therein). Varying demand has recently been discussed for durable goods and the corresponding strategies have been characterized (Board, 2008). The pricing problem of a durable-good monopoly has recently been investigated (Chien and Chu, 2008). Durable goods under monopoly have been extensively discussed (Sobel, 1991) as well as the commitment of firms (Dudine et al., 2006; Coury and Petkov, 2008). The price competitions of durable goods have been considered when introducing multiple markets (Guo and Villas-Boas, 2007). Upgrades of durable goods have also been considered (Anton and Biglaiser, 2013). In fact, upgrades of durable goods are extremely popular in society (Waldman, 2003). For example, computers and software are frequently upgraded. Also in the military field, for example, B-52 bombers produced in the USA in the 1950s are still in wide use today and are expected to be in use in the future, but the plane has been upgraded repeatedly in terms of electronics, weaponry, and other features. The theory of product upgrades was initially proposed by Fudenberg and Tirole (1998) based on a twostage game model. Johnson and Myatt (2003) further developed upgrade techniques with two-stage game techniques. Anton and Biglaiser (2013) recently extended the upgrades of durable goods to the infinite horizon.

The practical background and existing literature mentioned above motivate us to consider the effects of spatial competition on upgrades of durable goods. For example, Shen Zhen Shi Long Ke Industry Co. Ltd. produces large printers and some upgraded products, and the price of printers differs in regions. Alternatively, the price depends on the distance between the producer and consumers. That is, the company applies price discrimination in its pricing strategy with a further consideration of transportation costs. Apparently, the producer earns more profits by applying such a differentiated strategy on the printer market than uniform pricing.

The effects of spatial competition have been discussed in an early paper (Hotelling, 1929), and in some recent papers (Vogel, 2008; Larralde et al., 2009; Nie, 2011; Nie and Sun, 2015; Yang et al., 2018) with the references mentioned therein. Taking spatial competition into consideration, Krugman (1980) investigated the effects of trade policy and found that both scale economies and production differentiation relate to the patterns of trade, as well as welfare gains from trade policy. Vogel (2008) introduced product differentiation in spatial competition, and the results indicate that those firms with higher productivity are always more isolated than firms with relatively lower productivity. Chakravorty et al. (2011) considered the price of energy in the Hotelling model, and they found that both technological improvement and policy adjustment play important roles in the efficiency of emission reduction. Loginova and Wang (2011) discussed customized products in spatial competition and derived interesting conclusions, which imply that the probability of customization rises when the differentiation in quality among competing firms increases. Nie (2010) developed a technology spillover theory under spatial competition, leading to the conclusion that industrial clusters are more likely to be formed when technology spillovers are less prominent.

This paper focuses on upgrades of durable goods to spatial monopolies based on economic phenomena and contributes to existing literature in several aspects. 
When upgrades of durable goods are discussed, we refer to the model established by Fudenberg and Tirole (1998). By employing a two-stage Hotelling model, we prove that the monopoly has the motivation to launch upgraded versions with high quality instead of solely producing products with low quality. Regardless of the expenditures on product upgrading, such as R\&D activities and reorganization of production processes, the launch of an upgraded version based on a typical product instead of a new brand creates profits for enterprises. Interestingly, if the market structure is a monopoly, the monopoly would not make a commitment to either the high-quality product or the low-quality one, even though the introduction of the former brings about more profits for the producer. Furthermore, in the two-stage Hotelling model, the monopoly produces more of both products in a second stage.

The rest of this paper is organized as follows. The model of the spatial monopoly with durable goods is formally established in Section 2. The equilibrium pricing strategy as well as the product commitment of the monopoly are solved and analyzed in Section 3. Some concluding remarks and further research topics are given in the final section.

\section{The Model}

Here we focus on the upgrades of durable goods in a linear city by employing a Hotelling model. Assume that the total number of consumers is always fixed at $L>0$. The model consists of two stages. In the first stage, a firm enters the industry with one type of product of low quality, which is denoted as $L$. The corresponding costs per unit production are noted as $c_{L}>0$. In the second stage, this firm upgrades its product to a higher degree, which is labelled $H$. The costs per unit production of the high-quality product are $c_{H}>0$. We further denote that $c_{H}=c_{L}+c_{\Delta}$ while $c_{\Delta} \geq 0$. Here we assume that the marginal costs are constant without taking the cost structure into account in the profits of the monopoly. The most important reason for this assumption is that the returns to scale are assumed to be constant as the spatial monopoly is the sole producer for the total demand in a given period. The monopoly would expand its production until the returns to scale become constant. Meanwhile, considering the cost structure in the model would make the equilibrium more complicated while it is not a major concern in our analysis. Therefore, without loss of generality, we neglect the cost structure in the model.

All consumers on the market are indexed by $z \in[0,1]$. The monopoly is located at $z_{0} \in[0,1]$. We consider the utility function of consumers as follows. Given the price $p$ with the quality $V$ and the net income $\theta I$, the utility function of a representative consumer is given as follows

$$
u=f(V)-p-t D\left(z, z_{0}\right)+\theta I,
$$

where $f(V)$ satisfies the conditions $\partial u / \partial f(V)>0$ and $\partial^{2} u / \partial f(V)^{2}<0$. It is rational that, for a representative consumer, higher product quality yields more utility with a marginal diminishing effect. Also, $D\left(z, z_{0}\right)$ is the shortest arc length separating consumers $z$ and the monopoly. Meanwhile, $t$ denotes transportation costs per unit of distance, and there is a continuum of consumers indexed by $\theta \in[0,1]$. Notice that the net income $\theta I$ is considered 
in the utility function, implying that the utility of a representative consumer is determined by not only consumption decision but also income. In other words, the net income $\theta I$ has been transferred from an external constraint to an internal factor in this paper.

We assume that $V \in\left\{V_{L}, V_{H}\right\}$, where the low-quality product is denoted as $V_{L}$ and the high-quality product is denoted as $V_{H}$. Without loss of generality, there exists $V_{\Delta}>0$ satisfying $V_{H}=V_{L}+V_{\Delta}$, which indicates $f\left(V_{H}\right)>f\left(V_{L}\right)$ due to the positive marginal utility of quality. We assume $D\left(z, z_{0}\right)=\left|z-z_{0}\right|$ such that the model is tractable. The quadratic transportation costs are considered in some papers (Larralde et al., 2009). Furthermore, the discounting factor is always assumed to be 1 for simplification.

The parameter $\theta \in[0,1]$ is given by the cumulative distribution function $F(\bullet)$ with continuous density $f(\bullet)$. The hazard rate $f(\theta) /(1-F(\theta))$ is assumed to be non-decreasing to guarantee the concavity of the objective function, which is met by most standard distributions. Furthermore, for any $z$, the parameter $\theta \in[0,1]$ observes the same distribution.

The location of the monopoly is fixed in the two stages. For simplicity, we assume that $z_{0}=1 / 2$. Because consumers at each point are identical, this assumption is therefore rational and the problem is simplified to a certa in degree with this assumption. Furthermore, $z_{0}=1 / 2$. is also the optimal location under the monopoly market structure characterized as a monopoly. In this way, all consumers are distributed symmetrically in this linear city, which is more tractable.

As assumed, in the first stage, only low-quality products are produced. The objective function of both consumers and the monopoly are discussed as follows.

Consumers. Given the price with the low quality $p_{1}{ }^{L}$ and the quality of the product $V_{L}$, the consumer buys the product if the relation $\theta I-p_{1}^{L}-t D\left(z, z_{0}\right) \geq 0$ holds. That is, for a rational consumer, net income minus expenditures on buying and transport costs should be non-negative.

Monopoly. The monopoly aims to maximize its profits, which is given in detail as follows. Given the price with low quality $p_{1}{ }^{L}$ along with $q_{1}{ }^{L}$, the firm aims to maximize its profits.

$$
\pi_{1}=\left(p_{1}^{L}-c_{L}\right) q_{1}^{L} .
$$

Actually, $q_{1}^{L}$ is determined by (2) and $p_{1}^{L}$ along with $\theta I-p_{1}^{L}-t D\left(z, z_{0}\right) \geq 0$. Denote the demand in the first stage to be $d_{1}\left(p_{1}^{L}\right)$ and the quantity of the stores to be $S_{1}^{L}$ (to avoid high price in the second stage, consumers make stores). The quantity of products is $q_{1}^{L}=d_{1}\left(p_{1}^{L}\right)+S_{1}^{L}$. Figure 1 presents the monopoly pricing in the first stage in the linear city with the incomes $\theta I$ for some $\theta$.

In the second stage, not only low-quality products but also high-quality products are produced. Naturally, the decision-making processes of both consumers and the monopoly are different from those in the first stage. 


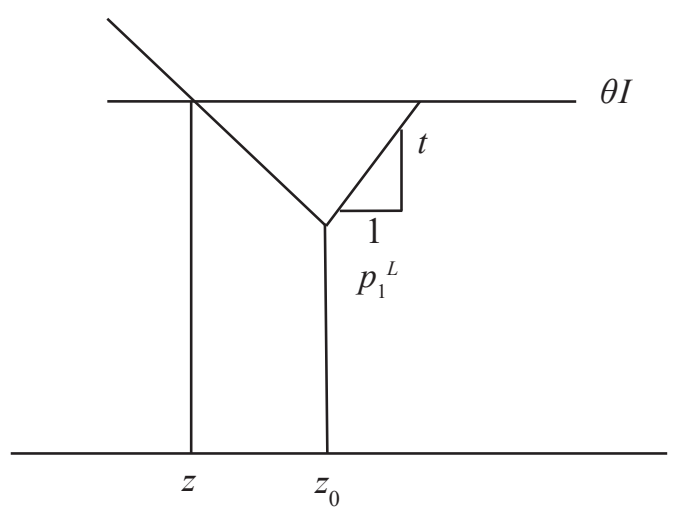

Note: $\theta I=$ net income; $t=$ transportation costs per unit of distance; $p_{1}{ }^{L}=$ the price of the product with low quality $z=$ spatial location of the consumer; $z_{0}=$ spatial location of the monopoly.

Source: Own calculation.

Consumers. In the second stage, given the price of the low quality $p_{2}{ }^{L}$ along with the quality of the product $V_{L}$, the price of the high quality $p_{2}^{H}$ along with the quality of the product $V_{H}$, and $p_{2}{ }^{H}>p_{2}{ }^{L}$, the consumer selects the low-quality product if one of the following formulations holds

$$
\begin{gathered}
\theta I-p_{2}^{H}-t D\left(z, z_{0}\right)<0 \text { and } \theta I-p_{2}^{L}-t D\left(z, z_{0}\right) \geq 0, \\
f\left(V_{L}\right)-p_{2}^{L}>f\left(V_{H}\right)-p_{2}^{H} \text { and } \theta I-p_{2}^{L}-t D\left(z, z_{0}\right) \geq 0 .
\end{gathered}
$$

Likewise, the consumer selects the high-quality product if the following formulation holds

$$
f\left(V_{L}\right)-p_{2}^{L} \leq f\left(V_{H}\right)-p_{2}^{H} \text { and } \theta I-p_{2}^{H}-t D\left(z, z_{0}\right) \geq 0 .
$$

Actually, if $f\left(V_{L}\right)-p_{2}^{L} \geq f\left(V_{H}\right)-p_{2}^{H}$ and $p_{2}^{H}>p_{2}^{L}$ simultaneously hold, then no consumers exist for the high-quality products. We therefore assume that $f\left(V_{L}\right)-p_{2}^{L} \geq f\left(V_{H}\right)-p_{2}^{H}$ never holds, or inequality (3') is neglected.

Monopoly. The monopoly aims to maximize its profits, which is specifically outlined as follows. Given the price of the low-quality product $p_{2}{ }^{L}$ along with the quantity $q_{2}{ }^{L}$, and the high-quality price $p_{2}{ }^{H}$ along with the quantity $q_{2}{ }^{H}$, the monopoly's profit function is presented as follows.

$$
\pi_{2}=\left(p_{2}^{L}-c_{L}\right) q_{2}^{L}+\left(p_{2}^{H}-c_{H}\right) q_{2}^{H} .
$$

Actually, $q_{2}{ }^{L}$ is determined by inequalities (3)-(4) and $p_{2}{ }^{L}$ along with $\theta I-p_{2}^{L}-t D\left(z, z_{0}\right) \geq 0$. Likewise, $q_{2}^{H}$ is determined by inequalities (3)-(4) and $p_{2}{ }^{H}$ along with $\theta I-p_{2}^{H}-t D\left(z, z_{0}\right) \geq 0$. 
Formulations (1)-(5) constitute upgrades of the durable goods for the spatial monopoly. When the monopoly makes decisions, it has to consider consumers' stores. The model will be further discussed formally in the next section.

\section{Primary Analysis}

The above Hotelling model with upgrading of durable goods under a monopoly is formally analyzed in this section. We first consider the consumer demand and then discuss the equilibrium of the two-stage dynamic model mentioned above. As the relation $q_{1}^{L}=d_{1}\left(p_{1}^{L}\right)+S_{1}^{L}$ holds, backward induction approaches are not suitable for addressing the above model.

\subsection{The demand}

We first analyze the above problem in the first stage. For Equations (1)-(2), the demand function is given according to the following formulation.

$$
\begin{aligned}
& d_{1}\left(p_{1}^{L}\right)=L \int_{0}^{1} \int_{\substack{\theta I-p_{1}^{L}-t D\left(z, z_{0}\right) \geq 0 \\
z \in[0,1]}} f(\theta) d z d \theta=L \int_{0}^{1} f(\theta) \min \left\{1, \max \left\{0, \frac{2\left(\theta I-p_{1}^{L}\right)}{t}\right\}\right\} d \theta \\
& =L \int_{\frac{p_{1}^{L}}{I}}^{\frac{p_{1}^{L}+0.5 t}{I}} f(\theta) \frac{2\left(\theta I-p_{1}^{L}\right)}{t} d \theta+L \int_{\frac{p_{1}^{L}+0.5 t}{I}}^{1} f(\theta) d \theta .
\end{aligned}
$$

Given the quantity of the stores $S_{1}^{L}$ without storing costs, the problem of the monopoly in the first stage is obtained by Equation (2) along with the following quantity $q_{1}^{L}=d_{1}\left(p_{1}^{L}\right)+S_{1}^{L}$ and the following profit function of the monopoly in the first stage.

$$
\pi_{1}=\left(p_{1}^{L}-c_{L}\right) q_{1}^{L}=\left(p_{1}^{L}-c_{L}\right)\left[L \int_{\frac{p_{1}^{L}}{I}}^{\frac{p_{1}^{L}+0.5 t}{I}} f(\theta) \frac{2\left(\theta I-p_{1}^{L}\right)}{t} d \theta+L \int_{\frac{p_{1}^{L}+0.5 t}{I}}^{1} f(\theta) d \theta+S_{1}^{L}\right] .
$$

We further point out that, to simplify the problem, no storing costs are considered, or $c_{s}=0$ always holds in this work. When the assumption $c_{s}=0$ does not hold, the result is similar and the analytic technique is also similar.

We further consider the second stage. For Equations (3)-(5), we have the following demand function.

$$
\begin{aligned}
& d_{2}^{L}\left(p_{2}^{L}, p_{2}^{H}\right)=L \int_{0}^{1} \int_{\substack{\theta I-p_{2}^{L}-t D\left(z, z_{0}\right) \geq 0 \\
\theta I-p_{2}^{H}-t D\left(z, z_{0}\right)<0 \\
z \in[0,1]}} f(\theta) d z d \theta \\
& =L \int_{0}^{1} f(\theta)\left[\min \left\{1, \max \left\{0, \frac{2\left(\theta I-p_{2}^{L}\right)}{t}\right\}\right\}-\min \left\{1, \max \left\{0, \frac{2\left(\theta I-p_{2}^{H}\right)}{t}\right\}\right\}\right] d \theta \\
& =L \int_{\frac{p_{2}^{L}}{I}}^{\frac{p_{2}^{H}}{I}} f(\theta) \frac{2\left(\theta I-p_{2}^{L}\right)}{t} d \theta+L \int_{\frac{p_{2}^{H}}{I}}^{\frac{p_{2}^{L}+0.5 t}{I}} f(\theta) \frac{2\left(p_{2}^{H}-p_{2}^{L}\right)}{t} d \theta+ \\
& +L \int_{\frac{p_{2}^{L}+0.5 t}{I}}^{\frac{p_{2}^{H}+0.5 t}{I}} f(\theta)\left[1-\frac{2\left(\theta I-p_{2}^{H}\right)}{t}\right] d \theta .
\end{aligned}
$$




$$
\begin{aligned}
& d_{2}^{H}\left(p_{2}^{L}, p_{2}^{H}\right)=L \int_{0}^{1} \int_{\substack{\theta I-p_{1}^{H}-t D\left(z, z_{0}\right) \geq 0 \\
z \in[0,1]}} f(\theta) d z d \theta=L \int_{0}^{1} f(\theta) \min \left\{1, \max \left\{0, \frac{2\left(\theta I-p_{2}^{H}\right)}{t}\right\}\right\} d \theta \\
& =L \int_{\frac{p_{2}^{H}}{I}}^{\frac{p_{2}^{H}+0.5 t}{I}} f(\theta) \frac{2\left(\theta I-p_{2}^{H}\right)}{t} d \theta+L \int_{\frac{p_{2}^{H}+0.5 t}{I}}^{1} f(\theta) d \theta .
\end{aligned}
$$

We further note that $\mathrm{S}_{1}^{L}$ is zero if $p_{1}^{L}>p_{2}^{L}$ and $S_{1}^{L}=d_{2}^{L}\left(p_{2}^{L}, p_{2}^{H}\right)$ if $p_{1}^{L}<p_{2}^{L}$. The problem of the monopoly in the second stage is determined by $q_{2}^{L}=d_{2}^{L}\left(p_{2}^{L}, p_{2}^{H}\right)-S_{1}^{L}$ and $q_{2}^{H}=d_{2}^{H}\left(p_{2}^{L}, p_{2}^{H}\right)$, which is therefore given as follows.

$$
\begin{aligned}
& \pi_{2}=\left(p_{2}^{L}-c_{L}\right)\left(L \int_{0}^{1} \int_{\substack{\theta I-p_{2}^{L}-t D\left(z, z_{0}\right) \geq 0 \\
\theta I-p_{2}^{H}-t D\left(z, z_{0}\right)<0 \\
z \in[0,1]}} f(\theta) d z d \theta-S_{1}^{L}\right)+L\left(p_{2}^{H}-c_{H}\right) \int_{0}^{1} \int_{\substack{\theta I-p_{2}^{H}-t D\left(z, z_{0}\right) \geq 0 \\
z \in[0,1]}} f(\theta) d z d \theta \\
&=\left(p_{2}^{L}-c_{L}\right)\left\{L \int_{\frac{p_{2}^{L}}{I}}^{\frac{p_{2}^{H}}{I}} f(\theta) \frac{2\left(\theta I-p_{2}^{L}\right)}{t} d \theta+L \int_{\frac{p_{2}^{H}}{I}}^{\frac{p_{2}^{L}+0.5 t}{I}} f(\theta) \frac{2\left(p_{2}^{H}-p_{2}^{L}\right)}{t} d \theta+\right. \\
&\left.+L \int_{\frac{p_{2}^{L}+0.5 t}{I}}^{\frac{p_{2}^{H}+0.5 t}{I}} f(\theta)\left[1-\frac{2\left(\theta I-p_{2}^{H}\right)}{t}\right] d \theta-S_{1}^{L}\right\}+ \\
&+L\left(p_{2}^{H}-c_{H}\right)\left[\int_{\frac{p_{2}^{H}}{I}}^{\frac{p_{2}^{H}+0.5 t}{I}} f(\theta) \frac{2\left(\theta I-p_{2}^{H}\right)}{t} d \theta+\int_{\frac{p_{2}^{H}+0.5 t}{I}}^{1} f(\theta) d \theta\right] .
\end{aligned}
$$

Here the demand based on Equations (6)-(10) is analysed. For the demand functions, Proposition 1 arises as follows.

Proposition 1. For the above demand functions, the following conclusions hold: $d_{1}\left(p_{1}^{L}\right)$ is monotonically decreasing in $p_{1}{ }^{L}$. Meanwhile, $d_{2}{ }^{L}\left(p_{2}^{L}, p_{2}^{H}\right)$ and $d_{2}^{H}\left(p_{2}^{L}, p_{2}^{H}\right)$ are monotonically decreasing in $p_{2}{ }^{L}$ and $p_{2}{ }^{H}$ respectively, while monotonically increasing in $p_{2}{ }^{H}$ and non-decreasing in $p_{2}{ }^{L}$ respectively.

Remarks: The above classic result apparently holds without taking spatial competition into account. It also holds in the spatial monopoly or when this result is extended to the spatial situation. Firstly, either the demand for the low-quality product or the demand for the one with high quality would be reduced if their price increases. Secondly, the low-quality product produced in the fist stage and the low-quality product produced in the second stage are substitutes to each other, indicating that an increase in the price of either one would stimulate the demand for the other one. Similarly, due to the substitution effect between the high-quality product and the low-quality product, it is not a surprising result that an increase in the price of low-quality products would reduce the demand for low-quality products in the second stage, thus stimulating the demand for the high-quality product. Considering that the decrease in demand for the low-quality product in the second stage may not transfer to the high-quality product, it is rational that $d_{2}{ }^{H}$ is at least non-decreasing in $p_{2}{ }^{L}$. 


\subsection{The equilibrium}

The equilibrium of the above model is considered. To simplify the problem, we always assume that $\theta$ observes the uniform distribution in this section, or $f\left(\theta_{1}\right)=f\left(\theta_{2}\right)$ for any $\theta_{1}$ and $\theta_{2}$. In the first stage, the first-order differential to the profit function of the monopoly is given by the following equation.

$$
\frac{d \pi_{1}\left(p_{1}^{L}\right)}{d p_{1}^{L}}=q_{1}^{L}+\left(p_{1}^{L}-c_{L}\right) \frac{d d_{1}\left(p_{1}^{L}\right)}{d p_{1}^{L}}=d_{1}\left(p_{1}^{L}\right)+S_{1}^{L}-\left(p_{1}^{L}-c_{L}\right) \frac{L}{t} \int_{\frac{p_{1}^{L}}{I}}^{\frac{p_{1}^{L}+0.5 t}{I}} f(\theta) d \theta .
$$

In the second stage, by virtue of Equation (10), the first-order differential to the profit function of the monopoly is given by the following equations.

$$
\begin{gathered}
\frac{\partial \pi_{2}}{\partial p_{2}^{L}}=\left[d_{2}^{L}\left(p_{2}^{L}, p_{2}^{H}\right)-S_{1}^{L}\right]+\left(p_{2}^{L}-c_{L}\right) \frac{\partial d_{2}^{L}\left(p_{2}^{L}, p_{2}^{H}\right)}{\partial p_{2}^{L}} . \\
\frac{\partial \pi_{2}}{\partial p_{2}^{H}}=d_{2}^{H}\left(p_{2}^{L}, p_{2}^{H}\right)+\left(p_{2}^{L}-c_{L}\right) \frac{\partial d_{2}^{L}\left(p_{2}^{L}, p_{2}^{H}\right)}{\partial p_{2}^{H}}+\left(p_{2}^{H}-c_{H}\right) \frac{\partial d_{2}^{H}\left(p_{2}^{L}, p_{2}^{H}\right)}{\partial p_{2}^{H}} .
\end{gathered}
$$

Here the concavity of the profit functions is discussed, which guarantees the existence of a solution to the above problems. In the first stage, for Equation (7), we have the following formulation.

$$
\begin{aligned}
& \frac{d^{2} \pi_{1}\left(p_{1}^{L}\right)}{d\left(p_{1}^{L}\right)^{2}}=\frac{d d_{1}\left(p_{1}^{L}\right)}{d p_{1}^{L}}-\frac{L}{t} \int_{\frac{p_{1}^{L}}{I}}^{\frac{p_{1}^{L}+0.5 t}{I}} f(\theta) d \theta-\left(p_{1}^{L}-c_{L}\right) \frac{L}{t}\left[f\left(\frac{p_{1}^{L}+0.5 t}{I}\right)-f\left(\frac{p_{1}^{L}}{I}\right)\right] \\
& =-\frac{2 L}{t} \int_{\frac{p_{1}^{L}}{I}}^{\frac{p_{1}^{L}+0.5 t}{I}} f(\theta) d \theta-\left(p_{1}^{L}-c_{L}\right) \frac{L}{t}\left[f\left(\frac{p_{1}^{L}+0.5 t}{I}\right)-f\left(\frac{p_{1}^{L}}{I}\right)\right] .
\end{aligned}
$$

In the second stage, for Equation (10), we have

$$
\begin{gathered}
\frac{\partial^{2} \pi_{2}}{\partial\left(p_{2}^{L}\right)^{2}}=2 \frac{\partial d_{2}^{L}\left(p_{2}^{L}, p_{2}^{H}\right)}{\partial p_{2}^{L}}+\left(p_{2}^{L}-c_{L}\right) \frac{\partial^{2} d_{2}^{L}\left(p_{2}^{L}, p_{2}^{H}\right)}{\partial\left(p_{2}^{L}\right)^{2}} \\
\frac{\partial^{2} \pi_{2}}{\partial\left(p_{2}^{H}\right)^{2}}=2 \frac{\partial d_{2}^{H}\left(p_{2}^{L}, p_{2}^{H}\right)}{\partial p_{2}^{H}}+\left(p_{2}^{L}-c_{L}\right) \frac{\partial^{2} d_{2}^{L}\left(p_{2}^{L}, p_{2}^{H}\right)}{\partial\left(p_{2}^{H}\right)^{2}}+\left(p_{2}^{H}-c_{H}\right) \frac{\partial^{2} d_{2}^{H}\left(p_{2}^{L}, p_{2}^{H}\right)}{\partial\left(p_{2}^{H}\right)^{2}} .
\end{gathered}
$$

According to Equations (18)-(20), we have the following conclusion about the con-cavity which guarantees the existence and the uniqueness of a solution to the model.

Proposition 2. For the above model, if $\theta$ observes the uniform distribution, the profit function of the monopoly in the first stage is concave in $p_{1}^{L}$, and the profit function of the monopoly in the second stage is also concave in $p_{2}^{L}$ and $p_{2}^{H}$.

Remarks: In the above conclusion, we assume that $\theta$ observes the uniform distribution such that $\frac{\partial^{2} d_{2}^{L}\left(p_{2}^{L}, p_{2}^{H}\right)}{\partial\left(p_{2}^{L}\right)^{2}}=0, \frac{\partial^{2} d_{2}^{L}\left(p_{2}^{L}, p_{2}^{H}\right)}{\partial\left(p_{2}^{H}\right)^{2}}=0, \frac{\partial^{2} d_{2}^{H}\left(p_{2}^{L}, p_{2}^{H}\right)}{\partial\left(p_{2}^{H}\right)^{2}}=0$, and 
$f\left(\frac{p_{1}^{L}+0.5 t}{I}\right)-f\left(\frac{p_{1}^{L}}{I}\right)=0$. Actually, the above conclusion holds for many other types of distributions. The above concavity guarantees the existence of a unique equilibrium for the system.

The equilibrium is then discussed. In the first stage, the solution is determined by the equation $\frac{\partial \pi_{1}}{\partial p_{1}^{L}}=0$ and the optimal strategies in the second stage are determined by the equations $\frac{\partial \pi_{2}}{\partial p_{2}^{L}}=0$ and $\frac{\partial \pi_{2}}{\partial p_{2}^{H}}=0$. By math calculation and comparison, we achieve the following relation.

Proposition 3. For the optimal price, if $\theta$ observes the uniform distribution, we have $p_{1}^{L}>p_{2}^{L}$ and $S_{1}^{L}=0$.

Remarks: The above result shows that the price of the lower-quality product will decrease if the higher-quality product is introduced. This is rational in the economic field, which is consistent with many social phenomena. Introduction of new products attracts some consumers, while it causes a reduction in the price of the lower-quality products. Such examples could easily be found when producers launch upgraded products to mainta in their market positions in fierce competition. For instance, after Apple announced to launch upgraded products, the price of its old-fashioned products would decrease significantly. Also, due to the fact that upgraded products have more functions with higher quality than the old ones, consumers always show greater interest in the new ones. Therefore, the producer could earn more profits while maintaining its market share by launching upgraded series of products. That explains why most enterprisers try to improve their products and launch upgraded products.

We further consider the profits of the monopoly in the two stages. It is apparent that the optimal strategy in the first stage is also a feasible strategy in the second stage. According to the property of the optimal problems, the following proposition arises.

Proposition 4. The profits of the monopoly are increased if an upgraded version of the durable goods is introduced, indicating that $\pi_{2} \geq \pi_{1}$.

Remarks: Due to the fact that the price of the upgraded version of the product is higher than that of the old version, the profits of the monopoly increase if an upgraded version of the durable goods is introduced. Definitely, a new version should claim a higher price than the old ones with characteristics such as higher quality, more functions, and faster operation. Also, investments in designing, testing, improving, producing and marketing are required before an upgraded version of a current product is formally launched. Therefore, the price of upgraded products is always higher than that of the old ones since the former satisfies consumers better while the producer needs to cover the costs of launching upgraded products.

The increase in the profits stimulates the development of upgraded products in many industries such as computer, mobile phone, car manufacturing, and so on. The increase 
in profits could be explained from two points of view. Firstly, the introduction of upgraded durable goods generates more consumer interest, thus enhancing the demand for total production. Secondly, due to the improvement in quality and function, upgraded goods are always set at a higher price than the old ones, indicating higher marginal profits yielded from selling. As a result, the monopoly producer earns more profits by launching upgraded products.

\section{The Commitment of the Monopoly}

The commitment of the monopoly is then considered. Similarly to the settings given by Johnson and Myatt (2006), we consider the possible commitment to either the high-quality product or the low-quality one. The commitment discussed in the paper by Fudenberg and Tirole (1998) is money back guarantee, which is different from that in the study conducted by Johnson and Myatt (2006).

Commitment to the low quality. It is apparent that the high-quality product should be introduced according to the results in Proposition 4. If the low-quality product is committed to, or no high-quality production is made in the second stage, the profits of the monopoly are lower than those with high-quality products.

We further consider the monopoly not introducing the high-quality product. When the storing costs are considered, the monopoly is going to make a commitment to the price in the second stage to reduce the stores (Dudine et al., 2006).

In this paper, when no storing costs are considered, a similar result holds. When the monopoly makes a commitment to the prices in the second stage such that $p_{1}^{L} \geq p_{2}^{L}$, the profits of the monopoly will increase or the monopoly obtains a non-negative commitment profit.

Commitment to the high quality. We further consider the monopoly whether the low quality product is produced or not in the second stage. In other words, the commitment to the high quality is considered. The commitment profits are also discussed.

Let the solution to Equations (11)-(13) be $p_{1}^{L,{ }^{*}}, p_{2}^{L, *}$ and $p_{2}^{H,{ }^{*}}$ along with the profits $\pi_{1}^{*}$ and $\pi_{2}^{*}$. If there is no low-quality product in the second stage, the solution is discussed. Denoting $S_{1}^{L}=d_{2}^{L}\left(p_{1}^{L}, p_{2}^{H}\right)$, the following profit functions are given in the two stages.

$$
\begin{gathered}
\pi_{1}^{c}=\left(p_{1}^{L}-c_{L}\right) q_{1}^{L}=\left(p_{1}^{L}-c_{L}\right)\left[L \int_{\frac{p_{1}^{L}}{I}}^{\frac{p_{1}^{L}+0.5 t}{I}} f(\theta) \frac{2\left(\theta I-p_{1}^{L}\right)}{t} d \theta+L \int_{\frac{p_{1}^{L}+0.5 t}{I}}^{1} f(\theta) d \theta+S_{1}^{L}\right], \\
\pi_{2}^{c}=L\left(p_{2}^{H}-c_{H}\right) \int_{\substack{\theta I-p_{2}^{H}-t D\left(z, z_{0}\right) \geq 0 \\
z \in[0,1]}}^{1} f(\theta) d z d \theta .
\end{gathered}
$$

Denoting the solution to Equations (17)-(18) to be $p_{1}^{L, c}$ and $p_{2}^{H, c}$ along with the profits $\pi_{1}^{c}$ and $\pi_{2}^{c}$, the following conclusion holds.

Proposition 5. $p_{2}^{L, *} \leq p_{1}^{L, c} \leq p_{1}^{L, *}$ and $p_{2}^{H, *} \geq p_{2}^{H, c}$. If the monopoly makes the commitment that the low-quality product will not be produced in the second stage, the monopoly obtains a non-positive commitment profit. 
Remarks: This conclusion shows that a rational monopoly is not willing to make a commitment on the high-quality product. Though the introduction of upgraded products with high quality increases profits, a commitment is not rational for the monopoly. Instead of solely producing upgraded products, the monopoly producer prefers to keep selling low-quality products as well as to launch upgraded ones. By such a strategy, it could gain more from producing and selling both types of products. Additionally, a commitment that the low-quality product will not be produced in the second stage has no effect on satisfying consumers. On the contrary, it may reduce profits and cause a potential market risk for the monopoly. Therefore, it would be a wise and rational strategy for the monopoly to keep away from making any commitment on production. Only in this way can the monopoly maximize its profits and satisfy consumers at the same time.

According to the above analyses of both the commitment to the high quality and the commitment to the low quality, the monopoly will undertake a loss. In summary, by virtue of the above two cases, we immediately have the following conclusion. This conclusion has been obtained for an oligopoly without spatial competition (Johnson and Myatt, 2006) and it also holds for the monopoly under spatial competition.

Proposition 6. The monopoly produces a positive quantity of both products in the second stage.

Remarks: This conclusion for an oligopoly illustrates that in the equilibrium, firms compete head-to-head. Under a monopoly, this result shows that all types of products are produced simultaneously in the second stage. This is consistent with economic phenomena in reality. For instance, Dell and other computer producers still produce some old-fashioned series after the upgraded versions are launched. Such production strategy is welfareimproving for both the monopoly producer and consumers. On the one hand, the monopoly producer could generate profits from not only the old-fashioned products but also the upgraded versions, implying that it can maximize profits while reducing the risk and uncertainty of selling new products. On the other hand, consumers also benefit from more alternatives on the market. Some consumers may show interest in upgraded products while others take the old ones due to their limited budget. As a result, it is rational for the monopoly to produce positive quantities of old-fashioned products as well as upgraded ones.

\section{Concluding Remarks}

This work characterizes the Hotelling model in a dynamic case combined with upgrades of durable goods under a monopoly. Establishing a two-stage Hotelling model, the equilibrium is discussed and the commitment of the monopoly is characterized. By mathematical calculation and comparison, major conclusions that are consistent with the practice arise. Firstly, the profits of the monopoly are improved by the introduction of the upgraded product, which could satisfy consumers better than the old ones. Secondly, the monopoly produces a positive quantity of both products in the second stage. The production strategy is welfare-improving for not only the producer but also consumers, 
indicating a maximization of profits for the producer and more alternatives for consumers. Thirdly, the monopoly would not make a commitment on either the high-quality products or the low-quality ones, while no consumers would store the low-quality products for future consumption. In practice, many social phenomena could be rationally explained by this dynamic Hotelling model, which could easily be found in the upgrading, pricing and production strategies in many industries.

There are some further topics relating to this work. It would be interesting to extend this work to multiple stages even for an infinite horizon. The strategies of firms are also extremely important for further consideration. Furthermore, it is also important to consider spatial competition for durable goods under other market structures. Moreover, government subsidy to product upgrading is also important in reality. In this aspect, we will refer to the significantly interesting papers of Chen, Wan and Wang (2015), Chen, Nie and Wang (2015), Nie (2013), and Yang and Nie (2015), in which different types of subsidies are significantly discussed to subsidize the agricultural sector and other industries with capacity constraints.

\section{Appendix}

Proof of Proposition 1. We first show that the demand function in the first stage $d_{1}\left(p_{1}^{L}\right)$ is monotonically decreasing in $p_{1}^{L}$. For the set $Z\left(p_{1}^{L}\right)=\left\{z \mid \theta I-p_{1}^{L}-t D\left(z, z_{0}\right) \geq 0, z \in[0,1]\right\}$, if $p_{1}^{L}<\bar{p}_{1}^{L}$, we immediately have $Z\left(p_{1}^{L}\right) \supseteq Z\left(\bar{p}_{1}^{L}\right)$ from the above definition of the set $Z\left(p_{1}^{L}\right)$ and the inequality $\theta I-p_{1}^{L}-t D\left(z, z_{0}\right)>\theta I-\bar{p}_{1}^{L}-t D\left(z, z_{0}\right)$. We correspondingly have

$$
d_{1}\left(p_{1}^{L}\right)=L \int_{0}^{1} \int_{\substack{\theta I-p_{1}^{L}-t D\left(z, z_{0}\right) \geq 0 \\ z \in[0,1]}} f(\theta) d z d \theta \geq d_{1}\left(\bar{p}_{1}^{L}\right)=L \int_{0}^{1} \int_{\substack{\theta I-\bar{p}_{1}^{L}-t D\left(z, z_{0}\right) \geq 0 \\ z \in[0,1]}} f(\theta) d z d \theta
$$

Namely, the demand function in the first stage $d_{1}\left(p_{1}^{L}\right)$ is monotonically decreasing with the price in this stage $p_{1}^{L}$. Similarly, we immediately have that $d_{2}^{L}\left(p_{2}^{L}, p_{2}^{H}\right)$ is monotonically decreasing with $p_{2}^{L}$ and monotonically increasing with $p_{2}^{H} \cdot d_{2}^{H}\left(p_{2}^{L}, p_{2}^{H}\right)$ is also monotonically decreasing with $p_{2}^{H}$ and non-decreasing with $p_{2}^{L}$. The result, which is the same as the classic conclusions in economics, is therefore obtained and the proof is complete.

Another alternative to testify Proposition 1 is given as follows. From Equations (6), (8) and (9), by direct calculation we have the following further relations.

$$
\begin{aligned}
& \frac{d\left(d_{1}\left(p_{1}^{L}\right)\right)}{d p_{1}^{L}}=\frac{L}{I t}\left[2\left(p_{1}^{L}+0.5 t\right) f\left(\frac{p_{1}^{L}+0.5 t}{I}\right)-2 p_{1}^{L} f\left(\frac{p_{1}^{L}}{I}\right)+2 p_{1}^{L} f\left(\frac{p_{1}^{L}}{I}\right)-2 p_{1}^{L} f\left(\frac{p_{1}^{L}+0.5 t}{I}\right)\right] \\
& -\frac{L}{I} f\left(\frac{p_{1}^{L}+0.5 t}{I}\right)-\frac{L}{t} \int_{\frac{p_{1}^{L}}{I}}^{\frac{p_{1}^{L}+0.5 t}{I}} f(\theta) d \theta=-\frac{L}{t} \int_{\frac{p_{1}^{L}}{I}}^{\frac{p_{1}^{L}+0.5 t}{I}} f(\theta) d \theta .
\end{aligned}
$$




$$
\begin{aligned}
& \frac{\partial\left(d_{2}^{L}\left(p_{2}^{L}, p_{2}^{H}\right)\right)}{\partial p_{2}^{L}}=-\frac{2 L}{t} \int_{\frac{p_{2}^{L}}{I}}^{\frac{p_{H}^{H}}{I}} f(\theta) d \theta+p_{2}^{L} \frac{2 L}{I} f\left(\frac{p_{2}^{L}}{I}\right)-\frac{2 L}{t} f\left(\frac{p_{2}^{L}}{I}\right) \frac{p_{2}^{L}}{I}- \\
& -\frac{2 L}{t} \int_{\frac{p_{2}^{H}}{I}}^{\frac{p_{2}^{L}+0.5 t}{I}} f(\theta) d \theta+\frac{L}{I} \frac{2\left(p_{2}^{H}-p_{2}^{L}\right)}{t} f\left(\frac{p_{2}^{L}+0.5 t}{I}\right)-\frac{L}{I} f\left(\frac{p_{2}^{L}+0.5 t}{I}\right)\left[1-\frac{2\left(p_{2}^{L}+0.5 t-p_{2}^{H}\right)}{t}\right. \\
& =-\frac{2 L}{t} \int_{\frac{p_{2}^{L}}{I}}^{\frac{p_{H}^{H}}{I}} f(\theta) d \theta-\frac{2 L}{t} \int_{\frac{p_{2}^{H}}{I}}^{\frac{p_{2}^{L}+0.5 t}{I}} f(\theta) d \theta=-\frac{2 L}{t} \int_{\frac{p_{2}^{L}}{I}}^{\frac{p_{2}^{L}+0.5 t}{I}} f(\theta) d \theta . \\
& \frac{\partial\left(d_{2}^{L}\left(p_{2}^{L}, p_{2}^{H}\right)\right)}{\partial p_{2}^{H}}=\frac{L}{I} \frac{2\left(p_{2}^{H}-p_{2}^{L}\right)}{t} f\left(\frac{p_{2}^{H}}{I}\right)+\frac{2 L}{t} \int_{\frac{p_{2}^{H}}{I}}^{\frac{p_{2}^{L}+0.5 t}{I}} f(\theta) d \theta-\frac{2 L\left(p_{2}^{H}-p_{2}^{L}\right)}{t I} f\left(\frac{p_{2}^{H}}{I}\right)+ \\
& +\frac{2 L}{t} \int_{\frac{p_{2}^{L}+0.5 t}{I}}^{\frac{p_{2}^{H}+0.5 t}{I}} f(\theta) d \theta+\frac{L}{I}\left[1-\frac{2\left(p_{2}^{H}+0.5 t-p_{2}^{H}\right)}{t}\right] f\left(\frac{p_{2}^{H}+0.5 t}{I}\right) \\
& =\frac{2 L}{t} \int_{\frac{p_{2}^{H}}{I}}^{\frac{p_{2}^{L}+0.5 t}{I}} f(\theta) d \theta+\frac{2 L}{t} \int_{\frac{p_{2}^{L}+0.5 t}{I}}^{\frac{p_{H}^{H}+0.5 t}{I}} f(\theta) d \theta=\frac{2 L}{t} \int_{\frac{p_{2}^{H}}{I}}^{\frac{p_{2}^{H}+0.5 t}{I}} f(\theta) d \theta . \\
& \frac{\partial\left(d_{2}^{H}\left(p_{2}^{L}, p_{2}^{H}\right)\right)}{\partial p_{2}^{L}}=0 . \\
& \frac{\partial\left(d_{2}^{H}\left(p_{2}^{L}, p_{2}^{H}\right)\right)}{\partial p_{2}^{H}}=-\frac{L}{t} \int_{\frac{p_{2}^{H}}{I}}^{\frac{p_{2}^{H}+0.5 t}{I}} f(\theta) d \theta .
\end{aligned}
$$

According to the equations given above, the conclusions in Proposition 1 all hold.

Proof of Proposition 3. Considering $\frac{\partial \pi_{1}}{\partial p_{1}^{L}}=0$ and $\frac{\partial \pi_{2}}{\partial p_{2}^{L}}=0$, we have that the optimal prices lie in the solution to the following system of equations.

$$
\begin{aligned}
& \frac{d \pi_{1}\left(p_{1}^{L}\right)}{d p_{1}^{L}}=d_{1}\left(p_{1}^{L}\right)+S_{1}^{L}-\left(p_{1}^{L}-c_{L}\right) \frac{L}{t} \int_{\frac{p_{1}^{L}}{I}}^{\frac{p_{1}^{L}+0.5 t}{I}} f(\theta) d \theta=0, \\
& \frac{\partial \pi_{2}}{\partial p_{2}^{L}}=\left[d_{2}^{L}\left(p_{2}^{L}, p_{2}^{H}\right)-S_{1}^{L}\right]+\left(p_{2}^{L}-c_{L}\right) \frac{\partial d_{2}^{L}\left(p_{2}^{L}, p_{2}^{H}\right)}{\partial p_{2}^{L}}=0 .
\end{aligned}
$$

We show $p_{1}^{L}>p_{2}^{L}$ by contradiction. If $p_{1}^{L}>p_{2}^{L}$ were false, we should have $p_{1}^{L} \leq p_{2}^{L}$.

Because $\theta$ observes the uniform distribution, we should

have $\int_{\frac{p_{1}^{L}}{I}}^{\frac{p_{1}^{L}+0.5 t}{I}} f(\theta) d \theta=\int_{\frac{p_{2}^{L}}{I}}^{\frac{p_{2}^{L}+0.5 t}{I}} f(\theta) d \theta$. If $p_{1}^{L} \leq p_{2}^{L}$ holds, by virtue

of Equations (6) and (8), we should have the relations $d_{2}^{L}\left(p_{2}^{L}, p_{2}^{H}\right)<d_{1}\left(p_{1}^{L}\right)$ and $d_{2}^{L}\left(p_{2}^{L}, p_{2}^{H}\right)-S_{i}^{L}<d_{1}\left(p_{1}^{L}\right)$. Furthermore, when $p_{1}^{L} \leq p_{2}^{L}$, we have 
$\left(p_{1}^{L}-c_{L}\right) \frac{L}{t} \int_{\frac{p_{1}^{L}}{I}}^{\frac{p_{1}^{L}+0.5 t}{I}} f(\theta) d \theta<\left(p_{2}^{L}-c_{L}\right) \frac{\partial d_{2}^{L}\left(p_{2}^{L}, p_{2}^{H}\right)}{\partial p_{2}^{L}}$. The following relation holds as $d_{1}\left(p_{1}^{L}\right)+S_{1}^{L}=\left(p_{1}^{L}-c_{L}\right) \frac{L}{t} \int_{\frac{p_{1}^{L}}{I}}^{\frac{p_{1}^{L}+0.5 t}{I}} f(\theta) d \theta$.

According to $d_{2}^{L}\left(p_{2}^{L}, p_{2}^{H}\right)-S_{i}^{L}<d_{1}\left(p_{1}^{L}\right)$ and $\int_{\frac{p_{1}^{L}}{I}}^{\frac{p_{1}^{L}+0.5 t}{I}} f(\theta) d \theta=\int_{\frac{p_{2}^{L}}{I}}^{\frac{p_{2}^{L}+0.5 t}{I}} f(\theta) d \theta$, we have $\left[d_{2}^{L}\left(p_{2}^{L}, p_{2}^{H}\right)-S_{1}^{L}\right]<d_{1}\left(p_{1}^{L}\right) \leq d_{1}\left(p_{1}^{L}\right)+S_{1}^{L}$ $=\left(p_{1}^{L}-c_{L}\right) \frac{L}{t} \int_{\frac{p_{1}^{L}}{I}}^{\frac{p_{1}^{L}+0.5 t}{I}} f(\theta) d \theta<\left(p_{2}^{L}-c_{L}\right) \frac{\partial d_{2}^{L}\left(p_{2}^{L}, p_{2}^{H}\right)}{\partial p_{2}^{L}}$.

Therefore, we have $p_{1}^{L}>p_{2}^{L} . S_{1}^{L}=0$ is correspondingly obtained according to the definition of $S_{1}^{L}$. The result is therefore obtained and the proof is complete.

Proof of Proposition 5. If the commitment that the low-quality product will not be produced in the second stage is made, we then have $S_{1}^{L}=d_{2}^{L}\left(p_{1}^{L}, p_{2}^{H}\right)$. The optimal conditions are given as follows.

$\frac{d \pi_{1}^{c}\left(p_{1}^{L}\right)}{d p_{1}^{L}}=d_{1}\left(p_{1}^{L}\right)+d_{2}^{L}\left(p_{1}^{L}, p_{2}^{H}\right)-\left(p_{1}^{L}-c_{L}\right) \frac{L}{t} \int_{\frac{p_{1}^{L}}{I}}^{\frac{p_{1}^{L}+0.5 t}{I}} f(\theta) d \theta-\left(p_{1}^{L}-c_{L}\right) \frac{d d_{2}^{L}\left(p_{1}^{L}, p_{2}^{H}\right)}{d p_{1}^{L}}=0$, $\frac{\partial \pi_{2}^{c}}{\partial p_{2}^{H}}=d_{2}^{H}\left(p_{2}^{L}, p_{2}^{H}\right)+\left(p_{2}^{H}-c_{H}\right) \frac{\partial d_{2}^{H}\left(p_{2}^{L}, p_{2}^{H}\right)}{\partial p_{2}^{H}}=0$.

By comparison, we immediately have the relation $p_{2}^{L, *} \leq p_{1}^{L, c} \leq p_{1}^{L, *}$ and $p_{2}^{H, *} \geq p_{2}^{H, c}$. We first show $p_{2}^{L, *} \leq p_{1}^{L, c} \leq p_{1}^{L, *}$ by virtue of the two equations given above and the conclusion of Proposition 3. According to the concavity of the profit functions as well as the relations $\frac{d \pi_{1}^{c}\left(p_{1}^{L}\right)}{d p_{1}^{L}}=\frac{d \pi_{1}\left(p_{1}^{L}\right)}{d p_{1}^{L}}+\left.\frac{\partial \pi_{1}\left(p_{2}^{L}, p_{2}^{H}\right)}{\partial p_{2}^{L}}\right|_{p_{1}^{L}=p_{2}^{L}}$, $\left.\frac{d \pi_{1}\left(p_{1}^{L}\right)}{d p_{1}^{L}}\right|_{p_{1}^{L}=p_{1}^{L, *}}=0,\left.\frac{\partial \pi_{1}\left(p_{2}^{L}, p_{2}^{H}\right)}{\partial p_{2}^{L}}\right|_{p_{2}^{L}=p_{2}^{L, *}}=0$ and $p_{2}^{L, *} \leq p_{1}^{L, *}$, we therefore have $p_{2}^{L, *} \leq p_{1}^{L, c} \leq p_{1}^{L, *}$. Similarly, we can obta in the relation $p_{2}^{H,{ }^{*}} \geq p_{2}^{H, c}$, the relation $\left(p_{2}^{L}-c_{L}\right) \frac{\partial d_{2}^{L}\left(p_{2}^{L}, p_{2}^{H}\right)}{\partial p_{2}^{H}}>0$, and the concavity of the profit functions.

Here we show that the monopoly obtains non-positive commitment profits if a commitment to the high-quality product is made. Obviously, according to the models, $p_{1}^{L}=p_{1}^{L, c}, p_{2}^{L}=p_{1}^{L, c}$ and $p_{2}^{H}=p_{2}^{H, c}$ are the feasible strategies. Furthermore, we have $\pi_{1}\left(p_{1}^{L, c}\right)+\pi_{2}\left(p_{1}^{L, c}, p_{2}^{H, c}\right)=\pi_{1}^{c}+\pi_{2}^{c}$. According to the definition of the profit functions, we 
immediately have $\pi_{1}^{*}+\pi_{2}^{*} \geq \pi_{1}^{c}+\pi_{2}^{c}$. Namely, if the monopoly makes a commitment that the low-quality product will not be produced in the second stage, the monopoly obtains non-positive commitment profits. No commitment on the low-quality product is made by the monopoly. The result is therefore obtained and the proof is complete.

\section{References}

Anton, J. J., Das, V. G. (2005). Storability, Market Structure, and Demand-shift Incentives. Rand Journal of Economics, 36(3), 520-543, https://doi. org/10.2139/ssrn.412601

Anton, J. J., Biglaiser, G. (2013). Quality, Upgrades and Equilibrium in a Dynamic Monopoly Market. Journal of Economic Theory, 148(3), 1179-1212, https://doi.org/10.1016/j. jet.2012.12.006

Barsky, R. B., House, C. L., Kimball, M. S. (2007). Sticky-price Models and Durable Goods. American Economic Review, 97(3), 984-998, https://doi. org/10.1257/aer.97.3.984

Board, S. (2008). Durable-goods Monopoly with Varying Demand. Review of Economic Studies, 75(2), 391-413, https://doi. org/10.1111/j.1467-937X.2008.00478.x

Chakravorty, U., Leach, A., Moreaux, M. (2011). Would Hotelling kill the Electric Car? Journal of Environmental Economics \& Management, 61(3), 281-296, https://doi.org/10.1016/j. jeem.2010.08.005

Chen, Y. H., Wan, J. Y., Chan, W. (2015). Agricultural Subsidy with Capacity Constraints and Demand Elasticity. Agricultural Economics, 61(1), 39-49, https://doi. org/10.17221/60/2014-AGRICECON

Chen, Y. H., Nie, P. Y., Wang, X. H. (2015). Asymmetric Duopoly Competition with Innovation Spillover and Input Constraints. Journal of Business Economics \& Management, 16(6), 1124-1139, https://doi. org/10.3846/16111699.2013.823104

Chien, H. K., Chu, C. Y. C. (2008). Sale or Lease? Durable-goods Monopoly with Network Effects. Marketing Science, 27(6), 1012-1019, https://doi. org/10.1287/mksc.1070.0356

Coury, T., Petkov, V. P. (2008). Delegation and Commitment in Durable Goods Monopolies. Games \& Economic Behavior, 63(1), 41-55, https://doi. org/10.1016/j.geb.2007.06.009

Dudine, P., Hendel, I., Lizzeri, A. (2006). Storable Good Monopoly: the Role of Commitment. American Economic Review, 96(5), 1706-1719, https://doi. org/10.1257/aer.96.5.1706

Fudenberg, D., Tirole, J. (1998). Upgrades, Trade-ins, and Buybacks. Rand Journal of Economics, 29(2), 235-258, https://doi. org/10.2307/2555887

Goering, G. E. (2008). Socially Concerned Firms and the Provision of Durable Goods. Economic Modelling, 25(3), 575-583, https://doi. org/10.1016/j.econmod.2007.10.001

Guo, L., Villas-Boas, J. M. (2007). Consumer Stockpiling and Price Competition in Differentiated Markets. Journal of Economics \& Management Strategy, 16(4), 827-858, https://doi. org/10.1111/j.1530-9134.2007.00159.x

Hotelling, H. (1929). Stability in Competition. Economic Journal, 39(153), 41-57, https://doi. org/10.2307/2224214

Johnson, J. P., Myatt, D. P. (2003). Multiproduct Quality Competition: Fighting Brands and Product Line Pruning. American Economic Review, 93(3), 748-774, https://doi. org/10.1257/000282803322157070

Johnson, J. P., Myatt, D. P. (2006). Multiproduct Cournot Oligopoly. Rand Journal of Economics, 37(3), 583-601, https://doi.org/10.1111/j.1756-2171.2006.tb00032.x 
Krugman, P. (1980). Scale Economies, Product Differentiation, and the Pattern of Trade. American Economic Review, 70(5), 950-959.

Larralde, H., Stehlé, J., Jensen, P. (2009). Analytical Solution of a Multi-dimensional Hotelling Model with Quadratic Transportation Costs. Regional Science \& Urban Economics, 39(3), 343-349, https://doi.org/10.1016/j.regsciurbeco.2009.01.001

Loginova, O., Wang, X. H. (2011). Customization with Vertically Differentiated Products. Journal of Economics \& Management Strategy, 20(2), 475-515, https://doi.org/10.2139/ ssrn. 1287440

Nie, P. Y. (2009). Commitment for Storable Goods under Vertical Integration. Economic Modelling, 26(2), 414-417, https://doi.org/10.1016/j.econmod.2008.08.008

Nie, P. Y. (2010). Spatial Technology Spillover. Economic Computation \& Economic Cybernetics Studies \& Research, 44(4), 213-223.

Nie, P. Y. (2011). Spatial Maintenance Goods under Monopoly. Economic Research-Ekonomska Istraživanja, 24(4), 16-26, https://doi.org/10.1080/1331677X.2011.11517486

Nie, P. Y. (2013). Innovation under Spatial Duopoly. Prague Economic Papers, 23(4), 474-486, https://doi.org/10.18267/j.pep.463

Nie, P. Y., Sun, P. (2015). Search Costs Generating Industrial Clusters. Cities, 42, 268-273, https://doi.org/10.1016/j.cities.2014.08.002

Sobel, J. (1991). Durable Goods Monopoly with Entry of New Consumers. Econometrica, 59(5), 1455-1485, https://doi.org/10.2307/2938375

Vogel, J. (2008). Spatial Competition with Heterogeneous Firms. Journal of Political Economy, 116(3), 423-466, https://doi.org/10.1086/589891

Waldman, M. (2003). Durable Goods Theory for Real World Markets. Journal of Economic Perspectives, 17(1), 131-154, https://doi.org/10.1257/089533003321164985

Yang, Y. C., Nie, P. Y. (2015). R\&D Subsidies under Asymmetric Cournot Competition. Economic Research-Ekonomska Istraživanja, 28(1), 830-842, http://dx.doi. org/10.1080/1331677X.2015. 1088791

Yang, Y. C., Nie, P. Y., Liu, H. T., Shen, M. H. (2018). On the Welfare Effects of Subsidy Game for Renewable Energy Investment: Toward a Dynamic Equilibrium Model. Renewable Energy, 121, 420-428, https://doi.org/10.1016/j.renene.2017.12.097 